Closing the Gateway: Street Closures, Bisected Geography, and Crime in St. Louis, MO

Corresponding Author:

Christopher G. Prener, Ph.D.

Assistant Professor of Sociology

Saint Louis University

chris.prener@slu.edu

ORCID - 0000-0002-4310-9888

Taylor Harris Braswell, M.A.

Ph.D. Student in Sociology

Northeastern University

braswell.t@husky.neu.edu

ORCID - 0000-0003-1201-1826

Kyle Miller, B.A.

Master's Student in Urban Planning and Public Health

Harvard University Graduate School of Design and T.H. Chan School of Public Health miller@gsd.harvard.edu

Joel P. Jennings, Ph.D.

Assistant Professor of Sociology

Saint Louis University

joel.jennings@slu.edu

Word Count: 7,152

This manuscript is currently under peer review. 


\title{
Closing the Gateway: Street Closures, Bisected Geography, and Crime in St. Louis, MO
}

\author{
Abstract \\ Where intersections would typically be open to two-way traffic, in hundreds in cases in St. \\ Louis, Missouri, they have been closed using concrete barriers or cul-de-sacs. In this paper, we \\ provide the most comprehensive data set of closures available, evaluate their location in the city, \\ and assess their association with contemporary violent crime patterns. We find that though City \\ legislation describes the barriers as crime reduction tools, they are associated with elevated \\ violent crime rates at the neighborhood-level today. This finding suggests significant limitations \\ with "defensible space" strategies in St. Louis and elsewhere for addressing crime.
}

\section{Keywords}

defensible space, urban sociology, St. Louis, street closures, crime 
Traversing any city can be a challenge for visitors and locals alike - one-way streets, limits placed on making turns at particular intersections, and poor signage can stymie even seasoned navigators. In St. Louis, it can be even more challenging still. Spread throughout neighborhoods in the city's midsection and in what locals call "North City" are concrete barricades that prevent traffic flow in one or both directions through certain intersections. They have been the subject of local fascination for decades. The City first installed many barriers in the mid-1970s under the administration of Mayor Vincent Schoemehl. Locals now refer to the barriers in some areas as "Schoemehl pots" (Thorsen, 2015; see Figure 1), paying homage to the man who helped create what one local website called a "city body at war with itself" (Allen, 2014).

\section{$<<<$ FIGURE 1 ABOUT HERE $>>>$}

"Defensible space" theory (Allen 2014) fits with the closures' manifest function as a crime prevention tool. Indeed, in recent legislation authorizing new closures, the Board of Aldermen bills typically note that closing a street will increase the surrounding neighborhood's safety. Though the Board of Aldermen authorizes new barriers through legislation, the City does not retain a systematic list of closures made by public works employees (Thorsen, 2015). Thus, systematically tracing the installations has been difficult for local reporters and writers interested in the phenomenon.

We, therefore, have two aims with this paper. First, we provide the most specific accounting to date of how St. Louis's urban geography has become a tangled web of closed streets. We have published a dataset of all known current and former closures 
within the city alongside this paper. Second, we offer two sets of statistical analyses that empirically evaluate the demographic characteristics associated with barrier density within neighborhoods and test the relationship between violent crime rates for St. Louis in 2016 and barrier density at the neighborhood level.

The relationship between barrier density and crime is most important because it speaks to one of the two core justifications for the street closures' very existence; the other is traffic control. We find that increased barrier density in neighborhoods is associated with higher numbers of violent crimes. This finding suggests that, whatever the past successes barriers may have had in addressing violent crime, they do not appear to be associated with lower crime rates today. We know of no other city that has implemented barriers in the numbers seen in St. Louis. Therefore, this finding speaks to the tenability of defensible space strategies more generally as a means for addressing violent crime. As we will outline, this paper revisits the notion of defensible space in the very place where the concept originated.

\section{Background}

Defensible Space Theory

St. Louis has the unique distinction of being not just the site of a large-scale implementation of Oscar Newman's ideas about defensible space but also as the birthplace of these ideas themselves. The proliferation of street closures in St. Louis is the product of a marriage between a city's declining demographic trajectory and a 
theory about how to create greater control of public space for residents. Oscar Newman is well known for his theory of "defensible space" and his involvement in Yonkers' housing desegregation court case. He began his career as an academic in St. Louis during the mid-1960s, teaching architecture at Washington University. He placed the origin of defensible space in St. Louis, noting that the idea of defensible space arose from the City's Pruitt-Igoe public housing project's demise. Newman also developed his suggestion of street closures as an anti-crime tactic in St. Louis based on his observations of private streets that had been closed by residents to thru traffic (Newman, 1996).

Following Newman $(1972,1996)$, we understand the intended function of street barriers and road closures as a means of increasing control over behavior within residential spaces. Delineating between private and public areas of cities is a core aspect of Newman's broader theory of defensible space. In seeking a clear distinction between public and private space for both inhabitants of a neighborhood and outsiders, Newman hopes to instill a home-grown sense of ownership and control for residents. As we have already noted, this need to control public space is a byproduct of an oft-repeated narrative about the infamous Pruitt-Igoe public housing complex. Looking at PruittIgoe, Newman argued that:

"Because all the grounds were common and disassociated from the units, residents could not identify with them. The areas proved unsafe. The river of trees soon became a sewer of glass and garbage. The mailboxes on the ground floor were vandalized. The corridors, lobbies, elevators, and stairs were 
dangerous places to walk. They became covered with graffiti and littered with garbage and human waste. The elevators, laundry, and community rooms were vandalized, and garbage was stacked high around the choked garbage chutes." (Newman, 1996, p. 10)

Newman argues that changes to the built environment can increase the space's territoriality — strengthening the sense of ownership residents have over their communities. He posits that these changes help residents better position themselves to be aware of and act against crime within their neighborhoods (Newman, 1972).

Newman does not stop at advocating for changes within the design of public housing. Creating "controlled enclaves" (Newman, 1996, p. 13) is another way to introduce a sense of ownership over public space within a neighborhood. Writing specifically about street closures, Newman argues that:

"One of the benefits of street closure and the creation of mini-neighborhoods is that it brings neighbors together in unified action to address their joint problems. It also focuses their attention on removing criminal activity from their communities." (Newman, 1996, p. 52)

He thus ties street closures directly to the management of public (or heretofore public) space and crime reduction, connections he made in initial research based on private streets in St. Louis (Newman, 1980; Newman et al., 1974).

Newman was not the only person to make these types of arguments in the 1970s. Criminologist C. Ray Jeffery also calls upon design disciplines to mitigate criminal activity through physical changes to space. With his intervention of Crime Prevention 
Through Environmental Design (CPTED), Jeffery (1971) suggests that crime occurs when presented with an opportunity. By limiting these opportunities, neighborhoods are less likely to become targets of criminal activity. Therefore, defensible space and CPTED aim to fortify the built environment and increase natural surveillance opportunities - drawing inspiration from Jane Jacob's idea of eyes on the street (Jacobs, 1961).

Principles of Defensible Space and CPTED have increased in popularity since emerging in the 1970s. By the mid-1990s, the United States Department of Housing and Urban Development heralded these methods as effective measures in small public housing sites, even commissioning Newman to compile case studies to demonstrate their efficacy (Cisneros, 1996; Newman, 1996). During this period, neighborhoods began to feature iron gates, dead-end streets, and flower-beds as both real and symbolic barriers separating their communities from others.

Despite the propagation of defensible space as a design strategy, the efficacy of 'designing out crime' remains contested. Studies suggest that while these crime prevention initiatives may impede crime within one community, crime continuesmerely displaced to an adjacent space (Gabor, 1981; Reppetto, 1976). Furthermore, due to their reliance on residents to come together to reduce crime, defensible space features have proven less effective in spaces where individuals have not developed a sense of belonging or established significant connections to other residents (Merry, 1981). 
Individuals are less inclined to protect communities of which they do not believe they are a member.

Wagner (1997) highlights the complexities of designing out crime in St. Louis, which sought to understand the implications of traffic pattern modifications in two adjacent neighborhoods. Wagner studied the effects of changes to traffic flow undertaken through an initiative called "Project Quiet Street." This effort blocked access to some streets running through the area identified in the study as 'West Neighborhood.' By comparing West Neighborhood with adjacent 'East Neighborhood,' which had similar demographics but did not participate in the program, Wagner found that reducing traffic flow in West Neighborhood may have been associated with decreasing burglary rates in the five years after the street modifications, though a causal argument cannot be made here. He likewise found that residents reported experiencing less fear of crime in their neighborhood.

Other studies examining defensible space suggest that personal familiarity with neighborhoods may pose a challenge for defensible space interventions. While changes to the built environment may help separate public and private spaces, individuals who identify themselves as a part of the community or frequent the area and wish to commit a crime may not be deterred (Brantingham \& Brantingham, 1993; Cohen \& Felson, 1979). Others (Atlas, 1991; Mawby, 1977) go further, arguing that defensible space and CPTED features may work to create offensive space for individuals committing illicit acts. Here, individuals still develop a sense of ownership of their neighborhood but use 
the defensible built environment for surveillance to work against other community residents.

\section{St. Louis}

One possible explanation for the mixed track record of defensible space could lie in St.

Louis itself. Defensible space seeks to address what Newman (1996) and others (Blake, 1977; Jencks, 1977) see as the monumental failure of design in Pruitt-Igoe. However, a counter-narrative suggests that the demise of Pruitt-Igoe was not ultimately a failure of design but the predictable outcome of structural inequality. St. Louis has been a laboratory for housing segregation and white flight. Both ultimately contributed to significant population loss (by 2017, the city's population was just $36 \%$ of its high in 1950), resulting in a limited municipal budget that has made maintaining public housing difficult (Gordon, 2009; Tighe \& Ganning, 2015). These dynamics, combined with a lack of sufficient federal funds for maintenance, it can be argued, all but ensured the demise of not just Pruitt-Igoe but the Robert Taylor Homes, Cabrini Green, and others (Bristol, 1991; Heathcott, 2012). They also help us understand rising crime patterns over the same period (see Figure 2). This narrative suggests that defensible space may have an inconclusive track record because the design itself is not the core issue. Instead, the social structures within which that design becomes realized has a far more significant effect on social patterns within the city. 
Nevertheless, the idea that Pruitt Igoe's design was to blame rapidly took hold (Bailey, 1965; Blake, 1977; Jencks, 1977) thus generating demand for Newman's ideas. In the shadow of Pruitt-Igoe's final destruction at the hands of dynamite and the wrecking ball, 1970s St. Louis became not just the inspiration for Newman's work but the site of early, vigorous implementation of these ideas. From 1977 through the early 1990s (and sporadically after that), St. Louis has erected at least 335 barriers, closing streets to through traffic to "enhance and increase the stability of the neighborhood adjacent to said street" (St. Louis City Ordinance 62459).

The City made these installations in response to what Newman described as a city tearing itself asunder:

"St. Louis in the mid-1960s was a city coming apart...It had one of the Nation's highest crime rates, but the private streets appeared to be oblivious to the chaos and abandonment taking place around them." (Newman, 1996, p. 13)

City planning documents from the early 1970s note both of these trends. The 1973 St. Louis Development Program lays out in stark terms the dramatic population loss many cities were experiencing, including growing rates of vacancy, tax delinquency, and violent crime. Critically, the report also notes:

"There are many streets whose primary purpose is not to carry through traffic. Their function is to serve residential neighborhoods safely. In recent years...there has been a growing tendency for extraneous traffic to usurp these local streets... [and this] has contributed to the debilitation of many residential neighborhoods. Consequently, new methods 
must be found to correct this unsatisfactory traffic condition" (City of St. Louis, 1973, p. 76).

Within approximately a year of the initial publication of Oscar Newman's (1972) work

about St. Louis, there was a deliberate expression of the need to close residential neighborhoods to traffic by the City of St. Louis. This plan endorsed closures as both crime prevention and traffic control strategies (see Wagner, 1997). The City's plan was followed by a second Newman publication, explicitly discussing the use of road closures a short time later (Newman et al., 1974).

Notably, the City has not maintained a master list of these closures (Thorsen, 2015). Therefore, our first aim is descriptive — to understand the geography of street closures in St. Louis. Our second objective is analytical and has two facets. We seek to understand the demographic factors associated with barrier installations and discern whether barriers are associated with violent crimes in the communities where they exist. We hypothesize that if street barriers are a successful policy tool for designing out crime, there should be a negative relationship between the number of barriers in a neighborhood and the number of violent crimes.

\section{Data and Methods}

\section{Data Sources}

Our data set is the product of four individual data sources. To locate street barriers, we identified an initial list of street barriers from a Washington University in 
St. Louis term paper that examined the barriers phenomenon (Waldron, 2010). ${ }^{1}$ From this list, we used the City's orthoimagery, Google Street View, and fieldwork visits to identify which barriers are still in place. Each barrier noted in the term paper was verified using various means, and we added new barriers identified during our checks to form a single list of known barriers. Checking against these additional sources resulted in a publicly available data set of point data describing the locations of barriers ${ }^{2}$ known to remain in existence as of $2017(\mathrm{n}=280)$ as well as those that were removed by the City at some past date $(\mathrm{n}=55)$.

In addition to these barriers data, we utilize data from several other sources. We obtained publicly available address-level crime data from the St. Louis Police Department. Our measure of storefront businesses, which have a relationship with crimes in some analyses (Bernasco \& Block, 2011), utilize the City Observatory's Store Front Index database. Finally, we sourced census tract-level demographic data from the 1950 and 1980 decennial censuses, as well as the 2016 American Community Survey 5year estimates. The decennial census data were used to construct explanatory variables for modeling demographic correlates of barriers in 1980, while the ACS data were used to construct control variables for modeling the relationship between barriers and violent crimes in 2016.

Census tracts can be a problematic unit of analysis because they are not stable throughout time, often being redrawn from census to census. To achieve a stable unit of analysis throughout time, we used the R package areal (C. Prener \& Revord, 2019) to 
interpolate tract-level data into one-square kilometer grid squares. This process utilized grid square-level data based on the census tracts that intersected with each grid square and the size of those intersections. The creation of the grid "fishnet" yielded a dataset with 205 grid squares with corresponding demographic attributes for 1980 and 206 grid squares for our remaining variables. This analytical data set is also available for public download as part of this manuscript's Open Science Framework repository. ${ }^{3}$

\section{Methods}

We conducted our initial descriptive analysis by mapping the point data for barrier locations using ArcGIS Desktop kernel density techniques. To address our second aim, we conducted our regression analyses in R (R Core Team, 2020). While spatial models for continuous variables are well established in the literature (see Anselin \& Rey, 2014), models for count data (including Poisson, negative binomial, and zero-inflated models) remain an ongoing development area. One technique to account for spatial autocorrelation in count models is "eigenvector filtering" (Helbich \& Jokar Arsanjani, 2015). This approach uses a global spatial weights matrix to develop one or more eigenvectors representing spatial relationships. These become independent variables in subsequent models. This modeling strategy utilizes the R packages MASS (Venables \& Ripley, 2002), pscl (Jackman, 2020; Zeileis et al., 2008), spatialreg (R. S. Bivand et al., 2013), and spdep (R. Bivand \& Wong, 2018). 
For these analyses, our two dependent variables were street barriers per grid square and violent crimes in 2016 per grid square. Because each variable was already spatially normalized because of their uniform size across each areal unit (except grid squares on the city's edges, which are smaller than a full square kilometer grid square and vary in size), we opted to preserve each dependent variable in count form rather than convert them into rates. The first set of models evaluate the relationship between barrier counts and demographic factors from 1980 when barrier installations began in earnest. Our second set of models evaluates the contemporary relationship as of 2016 between barriers and violent crime. We include descriptive statistics for all variables in Table 1.

\section{$<<<$ TABLE 1 ABOUT HERE $>>>$}

Due to the racialized development history of St. Louis, in which African American residents have been particularly marginalized (Gordon, 2009; Tighe \& Ganning, 2015), we included the proportion of African American residents in each grid square as a predictor. We reason that perceptions of racial threat (e.g., Eitle et al., 2002; Parker et al., 2005), in addition to the persistent marginalization of African American neighborhoods throughout the history of St. Louis (Johnson, 2020), has made grid squares with significant proportions of African American residents the target of more barrier installations as well as more crime.

\section{Results}


Spatial Distribution of Barriers and Violent Crimes

Both street barriers and violent crime occur unevenly in St. Louis. Though the mean street barrier count per grid square is 1.37 , the standard deviation is more than double it at 2.77. The kernel density map shown in Figure 3 provides visual specificity, showing dense concentrations of barriers in areas proximate to both sides of Delmar Boulevard. In contrast, barrier distribution in the northernmost and southeastern parts of the city are far more sparse. Figure 4 shows the distribution of street barriers and violent crimes across grid squares, which tells a similar story - the grid squares with the highest concentration of obstacles either straddle or are proximate to Delmar Boulevard. The mean number of violent crimes per grid square is 28.07 , but a standard deviation of 33.28 shows a similarly high level of variability. Figure 4 shows an overwhelming concentration of violent crime in North City and pockets of the city's southwestern portion. Large swaths of the southeastern part of the city are devoid of barriers and have relatively low amounts of violent crime.

$$
\begin{aligned}
& <<<\text { FIGURE } 3 \text { ABOUT HERE }>>> \\
& <<<\text { FIGURE } 4 \text { ABOUT HERE }>>>
\end{aligned}
$$

\section{Historic Neighborhood Factors and Barrier Locations}

Though the City began installing barriers in the late 1970s, our analysis of barrier data indicates the 1980s were when most installations occurred. Using demographic data from the 1980 Decennial Census to understand the current geography 
of barriers present allows us to model factors associated with barrier density. Our modeling strategy for barriers relies on count models. We evaluated both Poisson and negative binomial models and selected negative binomial regression because of overdispersion in Model 1 (see Table 2). ${ }^{4}$ In addition to compensating for overdispersion, Models 2 and 3 also provide a better fit for our data as evidenced by decreasing AIC and BIC values. Model 3 uses the "eigenvector filtering" technique to account for spatial autocorrelation's effect on Module 2's coefficients. The Moran's I values presented in Table 2 suggest that the eigenvectors removed some autocorrelation, though it remains to a degree in Model 3. Our interpretations will, therefore, focus on Model 3.

$$
<<<\text { TABLE } 2 \text { ABOUT HERE }>>>
$$

Of the factors included in these models, both population and vacancy are statistically significant predictors associated with the number of barriers in each grid square. A unit change in scaled population is associated with a 2.951 increase in the incident rate ratio $(\mathrm{IRR})$ for barriers $(\mathrm{p}<.001)$. Likewise, a one-point increase in scaled vacancy is associated with a 2.329 increase in the IRR for barriers $(\mathrm{p}<.001)$. Increasing population density, since the grid squares represent square kilometers, and increasing proportion of vacant units are associated with increases in the number of barriers in a given square. Notable, poverty, the racial composition of grid squares, and population change were not associated with the number of barriers. 
Since the 1980 decennial census, population loss has continued to shape St.

Louis's demographic trajectory. Given that installations mainly took place in the 1970s, it does not make temporal sense to model the relationship between barriers and contemporary demographics in a multivariate manner. Correlation coefficients, presented in Table 3, give a sense of how different demographic characteristics are related to barrier counts in each grid square.

\section{$<<<$ TABLE 3 ABOUT HERE $>>>$}

When we compare current demographic factors and barriers per grid square, population loss since 1950 stands out for its albeit weak relationship $(\mathrm{r}=-0.271, \mathrm{p}<$ 0.001) with barriers. By 2016, nearly every neighborhood in St. Louis had experienced at least some degree of population loss. This pattern is a departure from Model 3 in the prior section, which showed no significant relationship between population loss and barriers' original locations.

Beyond population loss, few demographic factors show associations with barrier counts per grid square. This lack of relationships is unsurprising given the geographic extent of barriers - they cut across a swath of majority African American, somewhat integrated, and majority-white neighborhoods. There is also a wide variance in the amount of vacancy and poverty in these neighborhoods, so the lack of significance is again unsurprising. That said, there is a weak negative relationship between owneroccupied housing and barriers $(\mathrm{r}=-0.162, \mathrm{p}<.05)$, with fewer owner-occupied units associated with higher counts of barriers. 


\section{The Relationship Between Barriers and Violent Crime}

While there may not be strong associations between current demographic conditions and barriers in St. Louis, that does not mean that barriers do not have contemporary relevance in the city. The number of streets that remain closed several decades after the widespread adoption of barriers as a strategy for addressing, at least in-part, violent crime means that the barriers may still influence that issue. Indeed, we believe that the city's violent crime rates (Smith \& Sandoval, 2019) form one contemporary reason for maintaining the closures. Understanding the relationship between barriers and violent crime represents both a test of defensible space as a theoretical concept and a practical policy question for St. Louis City officials.

As we discussed above, violent crimes themselves (much like barriers) do not occur evenly across the City of St. Louis. They follow a Poisson distribution at the gridsquare level - many grid squares have minimal violent crime while a few have large numbers of incidents each year. To understand the relationship between barriers and violent crime, we, therefore, pursue a modeling strategy to deal with both the distribution of violent crime counts and the presence of spatial autocorrelation by using both Poisson and negative binomial models. As with our prior models, we use eigenvector filtering as a means to address autocorrelation. Table 4 presents our Poisson, negative binomial, and negative binomial with eigenvector filtering models.

Overall, the negative binomial models provide a substantially better fit for these data 
than a standard Poisson model. Accounting for spatial autocorrelation provides some further improvement on model fit, as evidenced by decreasing AIC and BIC values as well as a smaller Morgan's I value. Given these metrics, Model 6 will be the focus of our description here.

\section{$<<<$ TABLE 4 ABOUT HERE $>>>$}

Our main effect, the relationship between the number of street barriers and the number of violent crimes in a given grid square, holds across all three models in Table 4. Model 6, which includes a correction for spatial autocorrelation, shows a positive relationship between the number of barriers and violent crimes $(\operatorname{IRR}=1.163, \mathrm{p}=$ 0.030). This relationship holds while accounting for other factors, including population, commercial properties, vacancy, and the grid square's estimated demographic makeup. As the number of barriers increases, so does the count of violent crimes after accounting for other factors. This pattern suggests that barriers do not fulfill their manifest function of eliminating crime. Instead, higher barrier density is associated with higher numbers of violent crimes. However, this pattern does not suggest that the barriers themselves cause violent crime, a point we return to in the discussion.

Several other factors are associated with violent crime as well, including the proportion of African American neighborhoods in St. Louis $(\operatorname{IRR}=1.778, \mathrm{p}<.001)$. Others have noted similar patterns both in St. Louis (Smith \& Sandoval, 2019), and these findings speak to the burden that violent crime places on particular communities. As with the placement of barriers themselves, this finding suggests that structural forces 
associated with violent crime have a disproportionate effect on historically marginalized communities in St. Louis. Those structural forces include population loss, which

decreases violent crime $(\mathrm{IRR}=0.721, \mathrm{p}<.001)$. It is not the grid squares most beset by population loss that experience violent crime, then, but rather squares with more minimal population loss since nearly every square in St. Louis has seen some degree of population loss since 1950 .

Our models also find that storefront businesses are associated with higher violent crime levels $(\mathrm{IRR}=1.342, \mathrm{p}<.001)$. This pattern matches other findings on the effect of businesses on where crime occurs (Bernasco \& Block, 2011). Population counts itself $(\mathrm{IRR}=2.689, \mathrm{p}<.001)$ are also a predictor of increased amounts of violent crime. In both cases, increasing residents and businesses are associated with an increased likelihood of violent crime. Notably, however, these factors do not explain away the relationship between street barriers and violent crime.

\section{Discussion}

As we noted previously, our goal with these analyses is two-fold: we seek first to describe where the City of St. Louis installed barriers and to examine the relationship between barriers and violent crime. We find that the City heavily concentrated barrier installations in a relatively narrow area of St. Louis along Delmar Boulevard. Delmar Boulevard is a widely recognized line of demarcation in many St. Louis residents' geographic imagination. The 'Delmar Divide' thus represents the spatial segregation of 
North City, which is predominantly African American, from the integrated communities of the central corridor and the predominantly white communities of South St. Louis. Analytically, we also aim to understand the relationship between neighborhood demographic factors and barrier density. We find that both population counts and vacancy proportions in 1980 were associated with grid squares' barrier counts.

Our other analytical goal is to understand the degree to which barrier density affects violent crime within neighborhoods. Following the longstanding aim of the barriers articulated in policy documents and the local media, our hypothesis anticipated a negative relationship between violent crime and barrier density at the neighborhood level. Counter to this hypothesis, we find evidence that not only are barriers not factors in decreasing crime, but they are associated positively with violent crime rates holding other factors related to crime rates constant.

Critically, there may be no causal relationship between barriers and crime. In this narrative, closures happen to be located in neighborhoods with higher crime rates and are merely ineffective at limiting crime within these spaces. However, such an argument would contradict their reason for existing as expressed in the City's Board of Alderman bills that have authorized recent closures. Whether barriers are, at worst, associated with higher crime rates or, at best, ineffective, they present a contradictory face - their official reason for existence as a crime prevention tactic does not hold with contemporary crime patterns, yet they remain entrenched throughout the city. 
St. Louis's street closures' persistence in this light is intriguing and an avenue for future work. It is likely that residents remain mostly unaware of their effectiveness (or lack thereof). It is also possible that the barriers' creation of cul-de-sacs appeals to residents for traffic safety reasons or because they desire the feel of a more suburban neighborhood. Both would provide strong public motivations for retaining the barriers despite their lack of impact on violent crime.

Nevertheless, we believe that our findings raise important questions for City officials. While there may be second-order benefits for residents who live on closed blocks, it is also possible to have second-order negative consequences. The City of St. Louis's Fire Chief, for example, explicitly condemned the closures in 2009 after a shooting on a closed street: "This has been an ongoing concern of the fire department's. We don't like [the barriers]. They severely impede what we do" (Allen, 2014). In light of our findings, City officials would do well to question whether the possible unintended consequences of delayed first responders are worth the continuation of these closures.

City officials should also consider what other unintended consequences of closures might exist, including inefficient public transit and school bus routes, the viability of businesses within neighborhoods with higher densities of closures, and the capital costs associated with maintaining and upgrading barriers over time. Given the significant challenges facing St. Louis, including segregation, crime, vacancy, and population loss (Gordon, 2009; C. G. Prener et al., 2018; Sandoval, 2013; Tighe \& Ganning, 2015), we wonder if more active crime prevention strategies might be more effective. These should 
include those interventions that address deep-seated social issues that deserve priority over the cost of maintaining these street closures.

Beyond the City of St. Louis, our findings suggest that cities should implement defensible space strategies like street closures with caution. They are in line with other analyses (Gabor, 1981; Reppetto, 1976) that question the efficacy of defensible space as a method for controlling crime. These data also provide a telling example of how even well-meaning interventions to reduce crime may not "design out" crime if they do not deal with more fundamental factors that drive violence in cities.

\section{Limitations}

One important caveat for our analyses is that we did not have address-level crime data when the most significant number of barriers were installed (from 1977 through the early 1990s). Thus, we cannot measure the degree to which the barriers themselves worked or did not work early in their existence. The overall trend in crime (see Figure 1) did continue, mostly unabated, after the barrier installations began. A second essential and related caveat is that we do not measure the hyper-local effects of barriers. It is possible that, while there is a positive relationship between barrier density and crime rates at the neighborhood level, closed blocks themselves experience less crime than neighboring blocks that remain open. This second caveat is the direction we intend to take in future research. A third caveat has to do with the spatial maldistribution of both population and violent crime in St. Louis, which leads to high standard deviations 
for both measures. These variations are an essential feature of our data that shapes our final results.

A fourth and final source of error lies within our demographic data. The American Community Survey's (ACS) five-year estimates are subject to a degree of error. This error can be compounded by the simultaneous aggregation and disaggregation of count data through the areal interpolation process. While we have tools to express the margin of error within the ACS, we lack similar ways to express the uncertainty of estimates created using areal weighted interpolation. This unquantified error is also an important source of limitation for our results.

\section{Conclusion}

Oscar Newman's defensible space theory is a product of St. Louis's mid-century history. Therefore, it is perhaps unsurprising that St. Louis also offers a large-scale implementation of defensible space in the street barriers that constrict swaths of the city's geography. The barriers scattered across the city's landscape are a testament not only to former Mayor Vincent Schoemehl, the elected official most closely associated with the barriers, but to Newman himself. We have developed the most comprehensive known list of closures in the city, and find that the density of closures is not associated with less crime in neighborhoods. Our finding is an important one for St. Louis, given that addressing crime is the argument being made explicitly in the legislation that authorizes more recent installations of barriers. For other municipalities that may be 
considering defensible space or other techniques to "design out" crime, our findings suggest that street closures are at best ineffective and at worst associated with higher rates of violent crime in neighborhoods. They may also have secondary effects on first responders' ability to reach the neighborhoods they serve. 


\section{Declaration of Interests}

The authors have no financial or business interests that are associated with this paper. 


\section{Notes}

${ }^{1}$ While perhaps unorthodox, the lack of a master list from the City of St. Louis necessitated this as a starting point. All barriers recorded from the original Waldron list were checked extensively to ensure that they corresponded to correct locations.

${ }^{2}$ Link to repository removed for peer review.

${ }^{3}$ Link to repository removed for peer review.

${ }^{4}$ It is worth noting that a substantial number of grid squares include no barriers at all, and we also evaluated zero-inflated models for their suitability. Comparisons using a Vuong test suggested that the zero-inflated models were not a substantial improvement on the negative binomial models. 


\section{Works Cited}

Allen, M. (2014, October 16). The City Body At War With Itself: Street Blockages in St. Louis. NextSTL. https://nextstl.com/2014/10/city-body-war-street-blockagesst-louis-2/

Anselin, L., \& Rey, S. J. (2014). Modern spatial econometrics in practice: A guide to GeoDa, GeoDaSpace and PySAL. GeoDa Press.

Atlas, R. (1991). Other Side of CPTED. Security Management. https://www.ncjrs.gov/App/abstractdb/AbstractDBDetails.aspx?id=143812

Bailey, J. (1965). The case history of a failure. Architectural Forum, 123(12), 23.

Bernasco, W., \& Block, R. (2011). Robberies in Chicago: A Block-Level Analysis of the Influence of Crime Generators, Crime Attractors, and Offender Anchor Points. Journal of Research in Crime and Delinquency, 48(1), 33-57. https://doi.org/10.1177/0022427810384135

Bivand, R. S., Pebesma, E., \& Gomez-Rubio, V. (2013). Applied spatial data analysis with R, Second edition. Springer, NY. http://www.asdar-book.org/

Bivand, R., \& Wong, D. W. S. (2018). Comparing implementations of global and local indicators of spatial association. TEST, $27(3), 716-748$.

Blake, P. (1977). Form Follows Fiasco: Why Modern Architecture Hasn't Worked. The Atlantic, 80-81.

Brantingham, P. L., \& Brantingham, P. J. (1993). Nodes, paths and edges: Considerations on the complexity of crime and the physical environment. Journal 
of Environmental Psychology, 13(1), 3-28. https://doi.org/10.1016/S0272-

$4944(05) 80212-9$

Bristol, K. G. (1991). The Pruitt-Igoe Myth. Journal of Architectural Education, 44(3), 163-171. https://doi.org/10.1080/10464883.1991.11102687

Cisneros, H. G. (1996). Defensible Space: Deterring Crime and Building Community. Cityscape, 15-33.

City of St. Louis. (1973). St. Louis Development Program. City of St. Louis.

Cohen, L. E., \& Felson, M. (1979). Social Change and Crime Rate Trends: A Routine Activity Approach. American Sociological Review, 44(4), 588-608. JSTOR. https://doi.org/10.2307/2094589

Eitle, D., D’Alessio, S. J., \& Stolzenberg, L. (2002). Racial Threat and Social Control: A Test of The Political, Economic, and Threat of Black Crime Hypotheses. Social Forces, 81(2), 557-576. https://doi.org/10.1353/sof.2003.0007

Gabor, T. (1981). The Crime Displacement Hypothesis: An Empirical Examination. Crime 85 Delinquency, 27(3), 390-404.

https://doi.org/10.1177/001112878102700306

Gordon, C. (2009). Mapping Decline: St. Louis and the Fate of the American City. University of Pennsylvania Press.

Heathcott, J. (2012). Planning Note: Pruitt-Igoe and the Critique of Public Housing. Journal of the American Planning Association, 78(4), 450-451.

https://doi.org/10.1080/01944363.2012.737972 
Helbich, M., \& Jokar Arsanjani, J. (2015). Spatial eigenvector filtering for spatiotemporal crime mapping and spatial crime analysis. Cartography and Geographic Information Science, 42(2), 134-148.

https://doi.org/10.1080/15230406.2014.893839

Jackman, S. (2020). pscl: Classes and Methods for $R$ Developed in the Political Science Computational Laboratory. United States Studies Centre, University of Sydney. https://github.com/atahk/pscl/

Jacobs, J. (1961). The Death and Life of American Cities. Random House.

Jeffery, C. R. (1971). Crime Prevention Through Environmental Design. SAGE Publications.

Jencks, C. (1977). The Language of Post-Modern Architecture. Rizzoli.

Johnson, W. (2020). The Broken Heart of America: St. Louis and the Violent History of the United States. Basic Books.

Mawby, R. I. (1977). Defensible Space: A Theoretical and Empirical Appraisal. Urban Studies, 14(2), 169-179. https://doi.org/10.1080/00420987720080321

Merry, S. E. (1981). Defensible Space Undefended: Social Factors in Crime Control Through Environmental Design. Urban Affairs Quarterly, 16(4), 397-422. https://doi.org/10.1177/107808748101600401

Newman, O. (1972). Defensible Space: Crime Prevention Through Urban Design. Macmillan.

Newman, O. (1980). Community of Interest. Anchor Press/Doubleday. 
Newman, O. (1996). Creating Defensible Space. DIANE Publishing.

Newman, O., Grandin, D., \& Wayno, F. (1974). The Private Streets of St. Louis. A National Science Foundation study. Institute for Community Design.

Parker, K. F., Stults, B. J., \& Rice, S. K. (2005). Racial Threat, Concentrated Disadvantage and Social Control: Considering the Macro-Level Sources of Variation in Arrests*. Criminology, 43(4), 1111-1134. https://doi.org/10.1111/j.1745-9125.2005.00034.x

Prener, C. G., Braswell, T. H., \& Monti, D. J. (2018). St. Louis's "urban prairie": Vacant land and the potential for revitalization. Journal of Urban Affairs, O(0), 1-19. https://doi.org/10.1080/07352166.2018.1474079

Prener, C., \& Revord, C. (2019). areal: An R package for areal weighted interpolation. Journal of Open Source Software, 4(37), 1221. https://doi.org/10.21105/joss.01221

R Core Team. (2020). R: A Language and Environment for Statistical Computing. $\mathrm{R}$ Foundation for Statistical Computing. https://www.R-project.org Reppetto, T. A. (1976). Crime Prevention and the Displacement Phenomenon. Crime $\mathcal{E}$ Delinquency, 22(2), 166-177. https://doi.org/10.1177/001112877602200204

Sandoval, J. S. O. (2013). Understanding the Demographic Hurdles to Revitalize Saint Louis. Saint Louis University Public Law Review, 33, 161-182. 
Smith, T. A., \& Sandoval, J. S. O. (2019). A Spatial Analysis of Homicides in Saint Louis: The Importance of Scale. Spatial Demography, 7(1), 57-82. https://doi.org/10.1007/s40980-018-00046-8

Thorsen, L. (2015, July 11). In a city where street closings are common, "Schoemehl pots" never seem to go away. St. Louis Post-Dispatch. https://www.stltoday.com/news/local/metro/in-a-city-where-street-closings-arecommon-schoemehl-pots/article_c191cf1a-4967-5f58-80f4-3d8e3189790f.html

Tighe, J. R., \& Ganning, J. P. (2015). The divergent city: Unequal and uneven development in St. Louis. Urban Geography, 36(5), 654-673. https://doi.org/10.1080/02723638.2015.1014673

Venables, W. N., \& Ripley, B. D. (2002). Modern Applied Statistics with S (Fourth). Springer. http://www.stats.ox.ac.uk/pub/MASS4/

Wagner, A. E. (1997). A study of traffic pattern modifications in an urban crime prevention program. Journal of Criminal Justice, 25(1), 19-30.

Waldron, S. (2010). Streets Not Thru. Washington University in St. Louis.

Zeileis, A., Kleiber, C., \& Jackman, S. (2008). Regression Models for Count Data in R. Journal of Statistical Software, 27(8). http://www.jstatsoft.org/v27/i08/ 


\section{Tables}

TABLE 1 - Descriptive Statistics per Grid Square in St. Louis

\begin{tabular}{|c|c|c|c|c|c|}
\hline Statistic & $\mathrm{N}$ & Mean & St. Dev. & Min & $\operatorname{Max}$ \\
\hline Barriers & 206 & 1.354 & 2.770 & 0 & 14 \\
\hline Violent Crimes, 2016 & 206 & 27.752 & 33.391 & 0 & 202 \\
\hline Population, 1980 & 206 & $2,199.199$ & $1,703.382$ & 0.000 & $6,032.584$ \\
\hline \% African American, 1980 & 205 & 40.286 & 38.148 & 0.000 & 98.662 \\
\hline \% Vacant, 1980 & 205 & 11.870 & 8.311 & 0.609 & 41.142 \\
\hline \% in Poverty, 1980 & 205 & 21.231 & 13.349 & 1.853 & 56.742 \\
\hline \% Population Change, 1950-1980 & 206 & -25.810 & 52.774 & -100.000 & 393.550 \\
\hline \% Population Change, 1950-2016 & 206 & -43.282 & 47.002 & -91.988 & 249.626 \\
\hline Population, 2016 & 206 & $1,528.481$ & $1,201.441$ & 0.037 & $4,975.198$ \\
\hline \% African American, 2016 & 206 & 55.202 & 33.556 & 1.521 & 98.166 \\
\hline \% in Poverty, 2016 & 206 & 27.737 & 12.804 & 4.363 & 61.167 \\
\hline \% Owner Occupied Homes, 2016 & 206 & 46.155 & 16.267 & 3.105 & 83.028 \\
\hline \% Vacant, 2016 & 206 & 23.661 & 12.051 & 0.293 & 55.120 \\
\hline Store Front Businesses & 206 & 5.189 & 7.360 & 0 & 43 \\
\hline
\end{tabular}


TABLE 2 - Modeling Barrier Density per Square Kilometer in St. Louis, 1980

\begin{tabular}{|c|c|c|c|}
\hline & \multicolumn{3}{|c|}{ Dependent variable: } \\
\hline & \multicolumn{3}{|c|}{ Barriers Count } \\
\hline & \multirow{3}{*}{$\begin{array}{l}\text { Poisson } \\
\qquad(1)\end{array}$} & \multirow{2}{*}{\multicolumn{2}{|c|}{$\begin{array}{l}\text { Negative } \\
\text { Binomial }\end{array}$}} \\
\hline & & & \\
\hline & & $(2)$ & (3) \\
\hline Population, 1980 & 2.451 & 2.502 & 2.951 \\
\hline & $\mathrm{t}=10.809^{* * *}$ & $\mathrm{t}=6.123^{* * *}$ & $\mathrm{t}=7.151^{* * *}$ \\
\hline \% African American, 1980 & 1.044 & 1.034 & 0.865 \\
\hline & $\mathrm{t}=0.470$ & $\mathrm{t}=0.173$ & $\mathrm{t}=-0.778$ \\
\hline \% Vacant, 1980 & 1.887 & 2.234 & 2.329 \\
\hline & $\mathrm{t}=7.661^{* * *}$ & $\mathrm{t}=4.497^{* * *}$ & $\mathrm{t}=4.962^{* * *}$ \\
\hline \% Poverty, 1980 & 1.187 & 1.384 & 1.549 \\
\hline & $\mathrm{t}=1.471$ & $\mathrm{t}=1.367$ & $\mathrm{t}=1.928$ \\
\hline \% Population Change, 1950-1980 & 0.522 & 0.749 & 0.770 \\
\hline & $\mathrm{t}=-2.808^{* *}$ & $\mathrm{t}=-1.055$ & $\mathrm{t}=-1.038$ \\
\hline Eigenvector 1 & & & 557.148 \\
\hline & & & $\mathrm{t}=3.567^{* * *}$ \\
\hline Eigenvector 2 & & & 92.386 \\
\hline & & & $\mathrm{t}=2.429^{*}$ \\
\hline Constant & 0.519 & 0.502 & 0.427 \\
\hline & $\mathrm{t}=-5.072^{* * *}$ & $\mathrm{t}=-4.151^{* * *}$ & $\mathrm{t}=-4.929^{* * *}$ \\
\hline$\overline{\mathrm{AIC}}$ & 631.658 & 495.626 & 482.885 \\
\hline BIC & 651.596 & 518.887 & 512.792 \\
\hline Moran's I & $0.215^{* * *}$ & $0.275^{* * *}$ & $0.252^{* * *}$ \\
\hline Observations & 205 & 205 & 205 \\
\hline Log Likelihood & -309.829 & -241.813 & -233.442 \\
\hline theta & & $0.627^{* * *}(0.139)$ & $0.759^{* * *}(0.171)$ \\
\hline
\end{tabular}

Note:

- ${ }^{*}=\mathrm{p}<.05 ;{ }^{* *}=\mathrm{p}<.01 ; * * *=\mathrm{p}<.001$

- All predictor variables have been scaled

- Incident risk ratios along with un-transformed $t$ values are presented in lieu of coefficients 
Table 3 - Pearson's r Correlation Coefficients, Barriers and Contemporary Demographic Measures

\begin{tabular}{|c|c|c|c|c|c|c|}
\hline & Barriers & $\begin{array}{c}\% \text { African } \\
\text { American, } \\
2016\end{array}$ & $\begin{array}{c}\% \text { in } \\
\text { Poverty, } \\
2016\end{array}$ & $\begin{array}{l}\text { \% Owner } \\
\text { Occupied, } \\
2016\end{array}$ & $\begin{array}{l}\% \text { Vacant, } \\
2016\end{array}$ & $\begin{array}{c}\text { \% Population } \\
\text { Change, 1950- } \\
2016\end{array}$ \\
\hline Barriers & 1.000 & & & & & \\
\hline $\begin{array}{l}\% \text { African } \\
\text { American }\end{array}$ & 0.122 & 1.000 & & & & \\
\hline $\begin{array}{l}\% \text { in } \\
\text { Poverty }\end{array}$ & 0.051 & $0.778^{* * *}$ & 1.000 & & & \\
\hline $\begin{array}{l}\% \text { Owner } \\
\text { Occupied }\end{array}$ & $-0.162^{*}$ & $-0.341^{* * *}$ & $\begin{array}{c}- \\
0.512^{* * *}\end{array}$ & 1.000 & & \\
\hline $\begin{array}{l}\% \text { Vacant } \\
\%\end{array}$ & 0.005 & $0.782^{* * *}$ & $0.756^{* * *}$ & $-0.298 * * *$ & 1.000 & \\
\hline $\begin{array}{l}\text { Population } \\
\text { Change }\end{array}$ & $-0.271^{* * *}$ & $-0.158^{*}$ & $-0.192^{* *}$ & $0.176^{*}$ & $-0.285^{* * *}$ & 1.000 \\
\hline
\end{tabular}


TABLE 4 - Modeling the Relationship Between Barrier Density and Violent Crime per Square

Kilometer, 2016

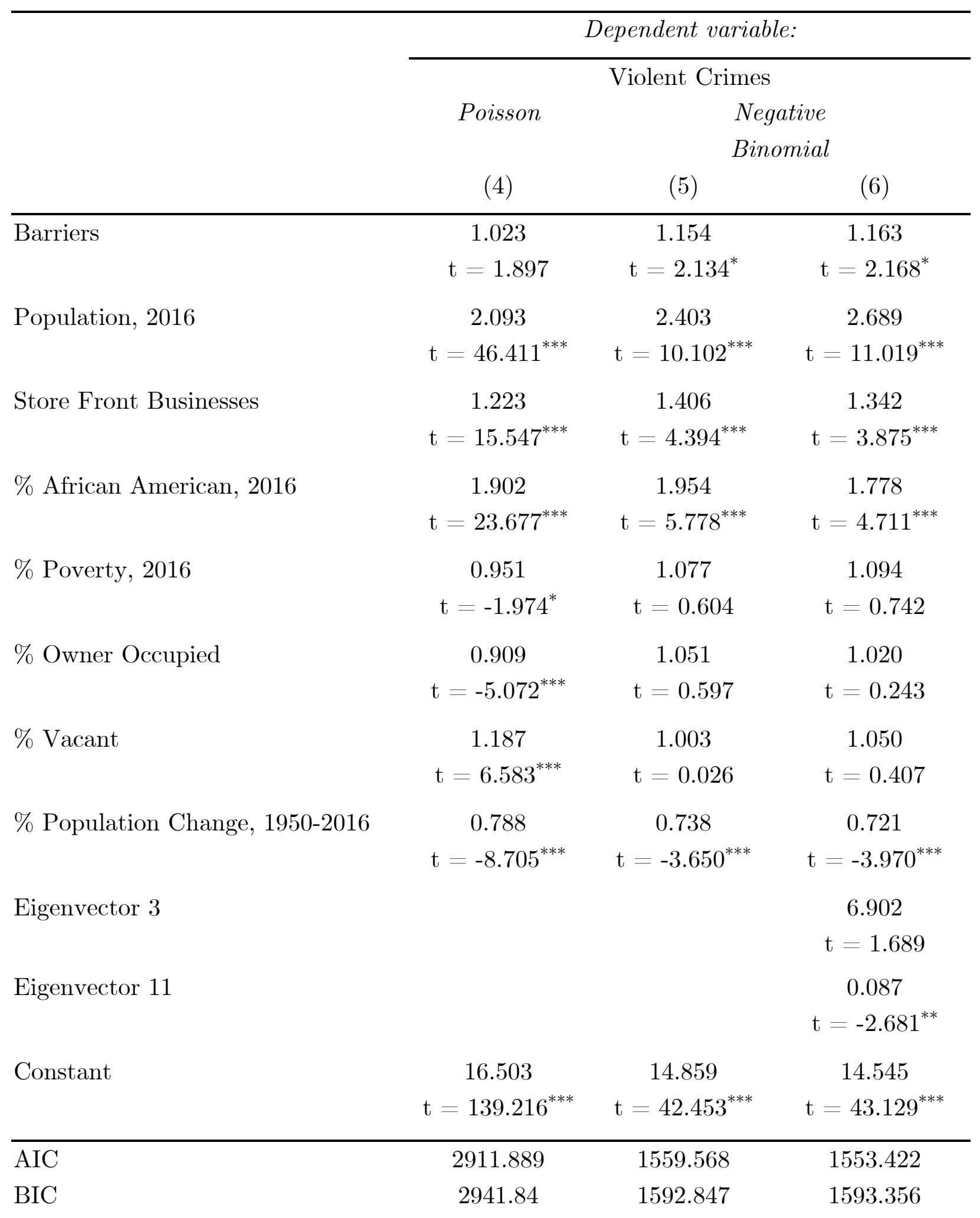


Moran's I

Observations

Log Likelihood theta
$0.114^{* *}$

206

$-1,446.945$

$$
0.131^{* * *}
$$

206

$-770.784$

$1.431^{* * *}(0.178)$
$0.100^{* *}$ 206

$-765.711$

Note:

- $*^{*}=\mathrm{p}<.05 ;{ }^{* *}=\mathrm{p}<.01 ;{ }^{* * *}=\mathrm{p}<.001$

- All predictor variables have been scaled

- Incident risk ratios along with un-transformed $t$ values are presented in lieu of coefficients 


\section{Figure Captions}

FIGURE 1 - "Schoemehl Pot" style street barriers in the Vandeventer neighborhood of St. Louis. These are concrete "pots" that are typically filled with soil and sometimes plantings.

FIGURE 2 - Trends in Population and Crime in St. Louis, 1960-2017

FIGURE 3 - K-density Map of Street Barriers in St. Louis

FIGURE 4 - Street Barriers and Violent Crimes (2016) per Square Kilometer in St. Louis 
Figure 1

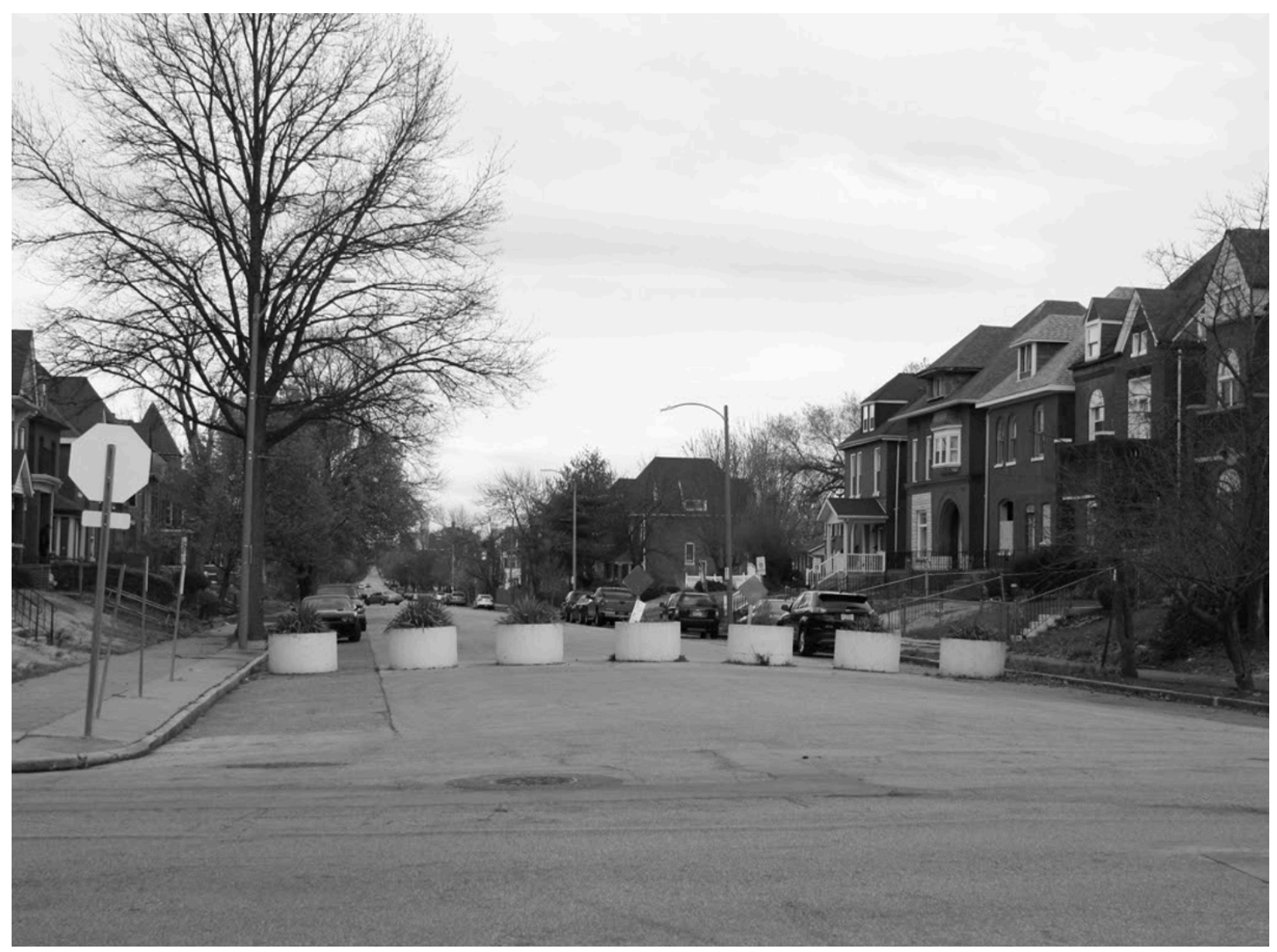


Figure 2

Population and Crime Rate, 1960-2017

St. Louis, MO
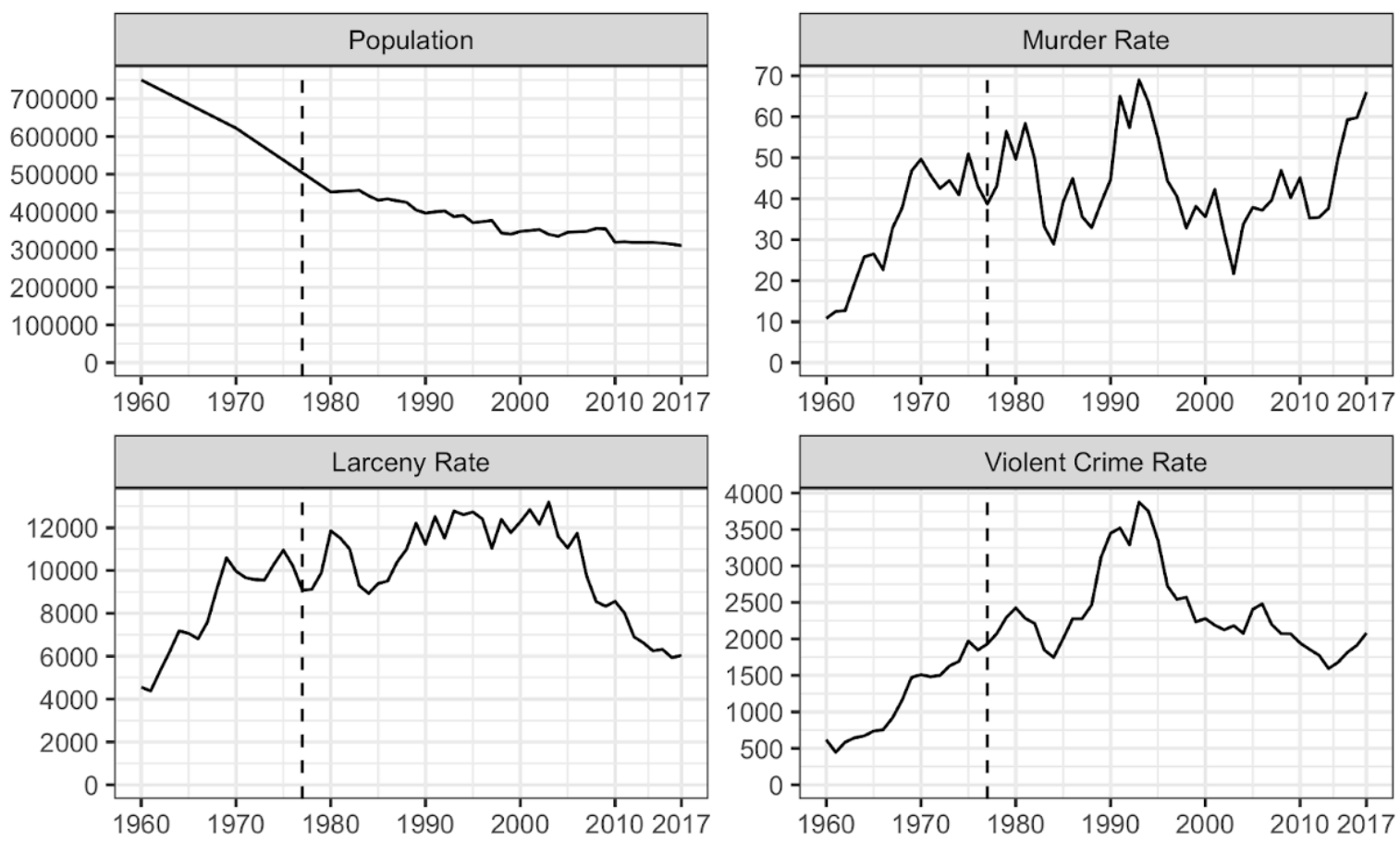

Vertical line represents first street barrier installation (1977).

Plot by Christopher Prener, Ph.D. 
Figure 3
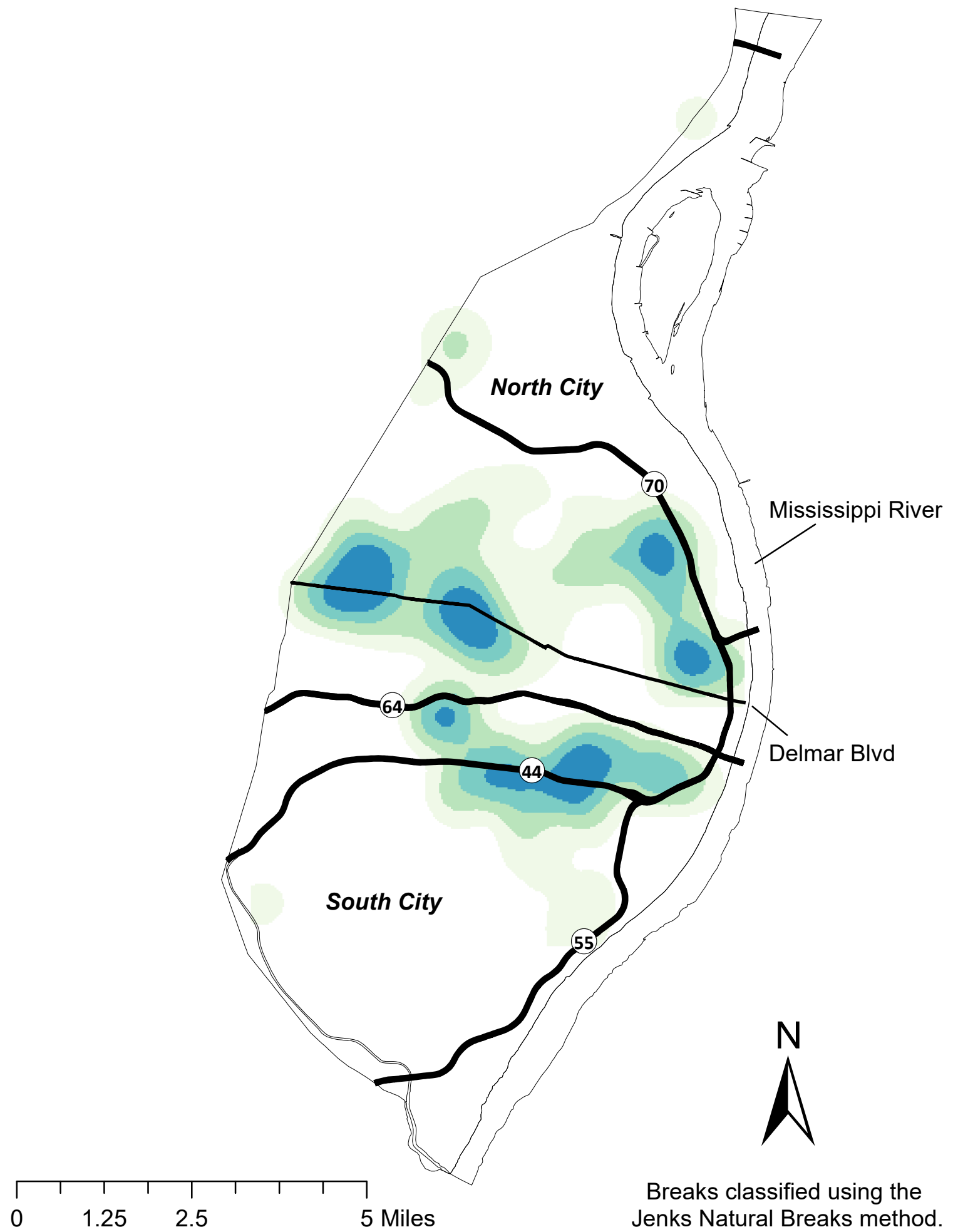

Breaks classified using the Jenks Natural Breaks method. 
Figure 4

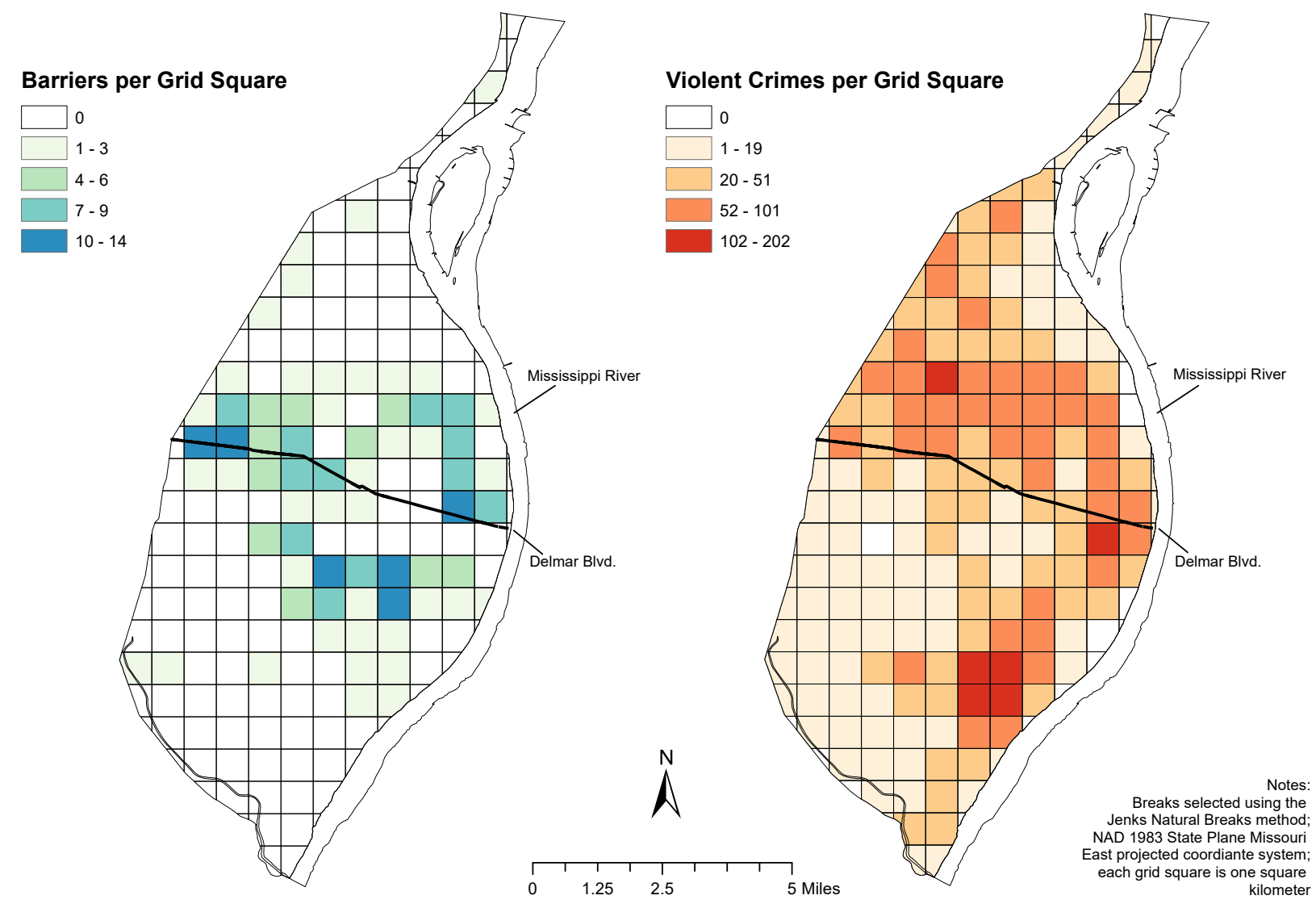

